\title{
Volume And Widening Ratio Trends of Sand Bed Channel Due to Bar Formation
}

\author{
D. A. Tholibon, J. Ariffin, J. Abdullah, Z. Othman, and M. Md Nujid
}

\begin{abstract}
Many studies have been dedicated to understand the physical mechanisms underlying the bar formation. This can be investigate by carried out an experimental work in an erodible sand bed channel using a large-scale physical river model. The study included the various hydraulic characteristics with steady flow rates and sediment supply. An experimental work consists of four matrices of flow rate and channel width with other variables namely grains size and bed slope were kept constant. Details of bar profile development that generated using Surfer, a software used for 3D elevation plots are included.
\end{abstract}

Index Terms-Bar formation, bar profile, Surfer software, widening ratio.

\section{INTRODUCTION}

More complicated transverse topographic expressions, like central or multiple row bars can be commonly found in wider channel reaches. In single-thread channels, researchers have generally recognized two bar types, namely free bars and forced bars [1]. The formation of river bars has been conclusively explained in terms of instability of erodible bed subject to turbulent flow in almost straight channels, which leads to the spontaneous development of bed perturbations. Therefore, the prediction works can be difficult, especially when it deals with wide-ranging rivers with different sediment properties and characteristics. The aims of this paper is to establish the plots of channel and bar profiles with respect to various experimental conditions using computer software Surfer and discuss the trend in term of volume changes and widening ratio.

\section{VARIABLES PROMOTES BAR FORMATION}

From the previous governing equation, it can be concluded that most repeating variables are the grain size properties $\left(d_{s}\right)$. Field and flume works have demonstrated that different size fractions of bed load are selectively routed around and over bar forms when in transport [2], [3], [4]. Ref. [5] found that nonuniform sediment has shown that sorting can occur at the initial motion or entrainment stage.

Manuscript received November 20, 2016; revised May 2, 2017. This work was supported by Ministry of Higher Education Malaysia (600RMI/RAGS 5/3 (176/2014)) and Research Management Institute (RMI) of Universiti Teknologi MARA, Shah Alam, Malaysia.

D. A. Tholibon and Z. Othman are with the Faculty of Civil Engineering, Universiti Teknologi Mara, 26400 Jengka, Pahang, Malaysia (e-mail: duratulaintholibon@gmail.com, zulhafizal445@pahang.uitm.edu.my).

J. Ariffin and J. Abdullah is with the Faculty of Civil Engineering, Universiti Teknologi Mara, 40000 Shah Alam, Selangor, Malaysia.

M. Md Nujid is with the Faculty of Civil Engineering, Universiti Teknologi Mara, 13500 Permatang Pauh, Pulau Pinang, Malaysia (e-mail: masyitahmn@ppinang.uitm.edu.my).
During transport, unlike entrainment, particle inertia and momentum can be important in determining which size are most strongly influenced by the near bed primary and secondary flow and thus which sizes ultimately are deposited [4]. The previous experimental works conclude that the larger sizes of grain sizes will contribute faster bar formation compared to finer sand sizes. Field observations by [6] have documented the decrease of sediment size and the spatial gradation in size from the upstream to the downstream end of the mid-channel bar during its temporal sequence of development. Sediment sorting is known to produce a damping effect of sorting processes on the height of alternate bars from both experiments [7], [8] and theoretical stability analysis [9].

The second significant repeating variable is width to depth ratio $\left(\frac{B}{D}\right)$. Various stability analyses showed that the relevant and crucial parameter to predict and controlling bar formation is the width to depth ratio $\left(\frac{B}{D}\right)$. In particular, bars form if $\left(\frac{B}{D}\right)$ exceeds a width to depth critical value, $\left(\frac{B}{D}\right)_{c}$, which depends on the Shields stress, $\tau^{*}$ and the dimensionless sediment size, $\mathrm{d}_{\mathrm{S}^{*}}$ [9] ; [10]; [11]. Free bars form above some threshold value of $\left(\frac{B}{D}\right)$ depending on both flow and sediment parameters. Within the context of a modified 2D approach, where vertical profiles of longitudinal velocity, eddy diffusivity and concentration are included, the critical value of $\left(\frac{B}{D}\right)$ for bar instability rapidly tends to infinity as $\tau^{*}$ increases beyond some threshold value, which increases with particle Reynolds number [9]. [12] found that the stable $\left(\frac{B}{D}\right)$ is a direct function of $\tau / \tau^{*}$ independent of flow rate and sediment properties. [13] found from their experimental work that slope of the sand tray gives less significant effect on the width to depth ratio and also on the overall bed width, which was a function mainly of water flow rate. The lower slope is insignificant to the mean active width, but the effect is apparent to the mean depth [14]. The increase in slope which took place with increasing load was also accompanied by an increase in roughness. Though slope was little affected by changes of total load in the flume experiments, there was some indication that at constant grain size, relatively steep slope is associated with small discharge and flat slope with large discharge [15]. Ref. [15] proposed the use of Equation 2.1 to determine slope for both the meandering and braided 
channels.

$$
S=0.06 Q_{b}^{-0.44}
$$

where $\mathrm{S}=$ bed slope, $\mathrm{Q}_{\mathrm{b}}=$ bank full discharge. In addition, for a given discharge, meanders is expected to occur on the smaller slopes. At the same slope, a braided channel will have a higher discharge than a meandering one.

Ref. [16] examined the behaviour of the model channel in a flume with respect to slopes and sediment loads. The findings indicated that the channel dramatically changes when the slope and sediment load exceed their threshold values. Slope and sediment load have high influence to the channel. The experiment with straight entrance conditions showed no tendency to meander until the slope was steepened to 0.004 . At slope above 0.004 a meanderingthalweg pattern was formed while at slope steeper than 0.016 , a braided channel developed.

Ref. [17] developed the theoretical threshold slope for braiding $\left(S_{t}\right)$ in which grain size has a significant effect:

$$
S_{t}=0.0049 Q^{-0.21} D_{50}^{0.52}
$$

$\mathrm{D}_{50}$ is the median particle diameter of the bed material.

Similarly, [18] generated empirical threshold based on unit stream power can be reworked as;

$$
S_{t}=0.272 Q_{b f}^{-0.5} D_{50}^{0.42}
$$

\section{THRESHOLD VELOCITY DETERMINATION}

The velocity which makes a few particles begin to move is called threshold (or initiation) of motion or incipient motion. Ref. [19] developed formulas to determine the critical mean flow velocity for particles in the range of $0.1 \mathrm{~mm}$ to $2 \mathrm{~mm}$ in water at $15^{\circ} \mathrm{C}, \rho_{\mathrm{s}}=2650 \mathrm{~kg} / \mathrm{m}^{3}$ and $\mathrm{g}=$ $9.81 \mathrm{~m} / \mathrm{s}^{2}$. The velocity can be determined by the formulae:

$$
\begin{aligned}
& V c=0.19\left(D_{50}\right)^{0.1} \log \left(\frac{12 R_{b}}{3 D_{90}}\right) \quad .100<\mathrm{D}_{50}<500 \mu \mathrm{m} \\
& V c=8.5\left(D_{50}\right)^{0.6} \log \left(\frac{12 R_{b}}{3 D_{90}}\right) .500<\mathrm{D}_{50}<2000 \mu \mathrm{m}
\end{aligned}
$$

where;

$\mathrm{D}_{50}$ is the diameter of bed material at $50 \%$ finer (in meters).

$\mathrm{D}_{90}$ is the diameter of bed material at $90 \%$ finer (in meters).

$\mathrm{R}_{\mathrm{b}}$ is hydraulic radius according to [20]. [21] used laboratory data collected by different investigators for determination of critical velocity by taking into consideration the incipient motion of sediment particles as shown in Equation 2.6 and Equation 2.7.

$$
\begin{gathered}
\frac{V_{c}}{\omega}=\frac{2.5}{\log \left(U_{*} d / v\right)-0.06}+0.66 \ldots \ldots \ldots . .1 .2<\frac{U_{*} d}{v}<70 \\
\frac{V c}{\omega}=2.05 \quad 70 \leq \frac{U_{*} d}{v}
\end{gathered}
$$

where $\mathrm{U}_{*}$ determined by $\left(\frac{\tau}{\rho}\right)^{1 / 2}$ and $\omega=\frac{1}{18}\left(\frac{\gamma_{s}-\gamma}{\gamma}\right) g \frac{d^{2}}{v}$

Ref. [22] developed Equation 2.8 of critical velocity for the uniform sediment (quartz in clear water at $20^{\circ} \mathrm{C}$ with specific gravity $\mathrm{SG}=2.65$ ) that more related to bridge piers scour.

$$
\frac{V_{c}}{U^{*}{ }_{c}}=5.75 \log \left(5.35 \frac{y}{D_{50}}\right)
$$

where $y$ is the flow depth and determination of critical shear velocity $\mathrm{U}{ }^{*}$ can be determined using the equation below;

$$
\begin{aligned}
U_{*_{c}} & =0.0115+0.0125 D_{50}{ }^{1.4} \ldots \ldots .0 .1 \mathrm{~mm}<D_{50}<1 \mathrm{~mm} \\
U_{*_{c}} & =0.0305 D_{50}{ }^{0.5}-0.0065 D_{50}{ }^{-1} \ldots \ldots \ldots .1 \mathrm{~mm}<D_{50}<100 \mathrm{~mm}
\end{aligned}
$$

However, [23] determine the critical velocity using Shields theory by assuming the Shields parameter, $\tau_{*}$ as 0.04 . The following Equation 2.11 is used to determine the shear velocity.

$$
U_{*}=\sqrt{\frac{\tau_{*} g d s}{0.6}}
$$

\section{A. Threshold Value Of Width To Depth Ratio}

Linear theory by [24] suggested that the bifurcation parameter for bar stability is width to depth ratio, hence the formation of free bars can be written in Equation 2.11.

$$
\beta>\beta_{c}\left(\theta_{o}, d_{s}\right)
$$

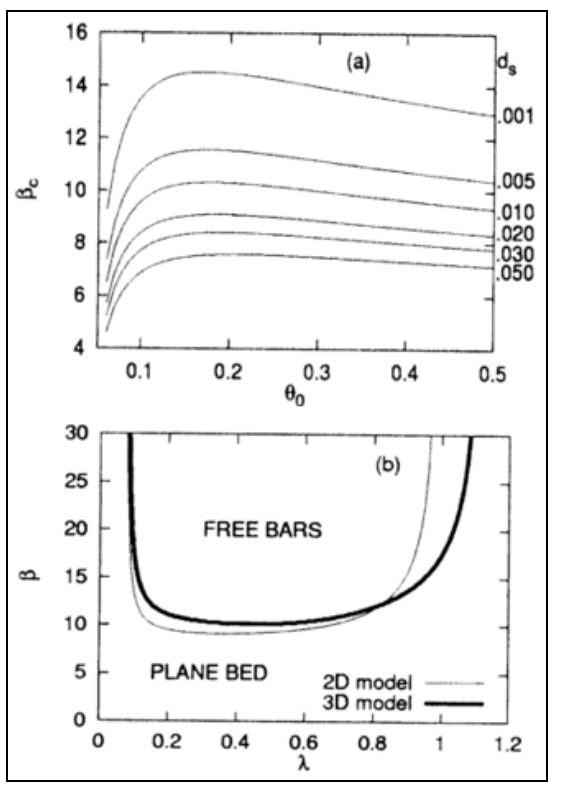

Fig. 1. Threshold value of width to depth ratio [24]

This indicates that threshold value of width to depth ratio, $\beta c$ depends on the reference values of Shields stress and roughness parameter as shown in Figure 1 (a). A comparison with available data from flume experiments by [22] performs satisfactorily except for values of Shields stress that close to the threshold for sediment movement.

Where $\beta$ is larger than its critical value, bar perturbations characterised by different value of longitudinal length can be enhanced, provided their wavenumber $\lambda$ falls within the unstable range defined as the region enclosed within the marginal curves as illustrated in Figure 1 (b). The figure 
also demonstrated that 2D model and 3D model do not show obvious differences and this indicates that secondary flows have little significance. Both models illustrate that formation of free bars at critical values of width to depth ratio in the range of 10 to 15 .

\section{B. Determination Of Shields Parameter}

Shields parameter can be determined through the Shields diagram as shown in Figure 2 [23]. The critical values of the Shields parameter $\tau_{*_{\mathrm{c}}}$ can be approximated as follows:

$$
\tau_{*_{c}} \approx 0.3 e^{\frac{-d_{*}}{3}}+0.06 \tan \phi\left(1-e^{\frac{-d_{*}}{20}}\right)
$$

where;

$$
d_{*}=d_{s}\left[\frac{(G-1) g}{v^{2}{ }_{m}}\right]^{1 / 3}
$$

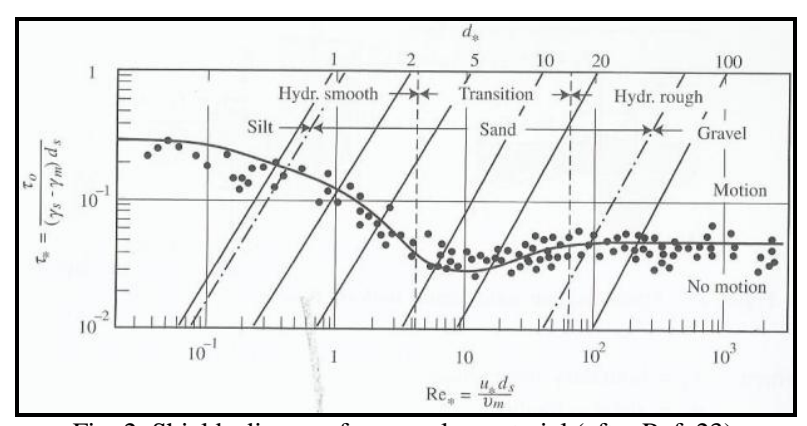

Fig. 2. Shields diagram for granular material (after Ref. 23).

Based on a comparison of data from Highway Research Board (1970) indicates the relationship between critical shear stress $\tau_{\mathrm{c}}$ with equivalent values for granular material as depicted in Table I.

\begin{tabular}{|c|c|c|c|c|c|c|}
\hline Class name & $\begin{array}{l}\mathrm{d}_{\mathrm{s}} \\
(\mathrm{mm})\end{array}$ & $\mathrm{d}_{*}$ & $\begin{array}{l}\phi \\
(\operatorname{deg})\end{array}$ & $\tau_{*_{\mathrm{c}}}$ & $\begin{array}{l}\tau_{\mathrm{c}} \\
(\mathrm{Pa})\end{array}$ & $\begin{array}{l}\mathrm{U}_{*_{\mathrm{c}}} \\
(\mathrm{m} / \mathrm{s})\end{array}$ \\
\hline Very coarse & $>1$ & 25 & 32 & $\begin{array}{l}0.02 \\
9\end{array}$ & 0.47 & $\begin{array}{l}0.02 \\
16\end{array}$ \\
\hline Coarse & $>0.5$ & $\begin{array}{l}12 . \\
5\end{array}$ & 31 & $\begin{array}{l}0.03 \\
3\end{array}$ & 0.27 & $\begin{array}{l}0.01 \\
64\end{array}$ \\
\hline Medium & $>0.25$ & 6.3 & 30 & $\begin{array}{l}0.04 \\
8\end{array}$ & $\begin{array}{l}0.19 \\
4\end{array}$ & $\begin{array}{l}0.01 \\
39\end{array}$ \\
\hline Fine & $>0.125$ & 3.2 & 30 & $\begin{array}{l}0.07 \\
2\end{array}$ & $\begin{array}{l}0.14 \\
5\end{array}$ & $\begin{array}{l}0.01 \\
2\end{array}$ \\
\hline Very fine & $\begin{array}{l}>0.062 \\
5\end{array}$ & 1.6 & 30 & $\begin{array}{l}0.10 \\
9\end{array}$ & 0.11 & $\begin{array}{l}0.01 \\
05\end{array}$ \\
\hline
\end{tabular}

TABLE I: THE THRESHOLD CONDITIONS FOR SAND AT $20^{\circ} \mathrm{C}$ [23]

\section{Determination Of Equilibrium State Of Bar Formation}

Ref. [24] determine the equilibrium state bar edges of sand grains that were generated with increasing height. Ref [20] had established the equilibrium state by determining the occurrence of first channel bifurcation. The equilibrium state is reached when the bed slope is equal to the water surface slope of which, the flow discharge and bar features had reached nearly constant values [7]. Flow discharge and feed rate of a mixture of sand and gravel (used also for bed material) were held constant until equilibrium between feed and bed load output was achieved [3]. Ref [11] identified that the steady state configuration was established when the number of new bifurcations equals on average the number of abandoned branches.

\section{Sectional Volume and Widening Ratio Change}

Cross section profile development of the different matrices of flow rates and channel width were generated using a function in Surfer as shown in Figure 3 (a) to (1). The analysis were made by generates the cross section profiles for each $0.5 \mathrm{~m}$ interval. The changes of bed configuration for each cross section can be deduced from the profiles by comparing from day one till the end of experiment. The initial cross section profile before the experimental run were in rectangular shape. As soon the flow were imposed to the channel, the bank were collapsed and formed the trapezoidal section.

The channel changes of the surfer profiles were describe as follows;

\section{1) Channel width $=20 \mathrm{~cm}, Q 1=4.97 \mathrm{~m}^{3} / \mathrm{hr}$}

At day 1 , the increasing width at upstream bend lead to decreasing of volume at $5.5 \mathrm{~m}$. A very small volume and widening ratio changes towards the downstream channel due to low flow. Day 2 presents the expansion of the upstream bend was observed between $6 \mathrm{~m}$ to $7.5 \mathrm{~m}$ due to cut-off process. The cut-off process generates the increasing volume at $6 \mathrm{~m}$ until $8.5 \mathrm{~m}$. The widening and volume fluctuate due to the formation of alternate bars that leads to erosion one of the channel bank. At day 4 the volume and width start to increase from point $6 \mathrm{~m}$ to $7.5 \mathrm{~m}$ due to the cutoff process of upstream bend. At day 5, local deposition at distance $11 \mathrm{~m}$ was observed and contributed to the increasing of volume at the downstream reach. Higher widening ratio at $10 \mathrm{~m}$ lead to local deposition at distance $11 \mathrm{~m}$. Day 6 indicates the highest volume at point $7 \mathrm{~m}$. Deposition grew in size and remained stable which had subsequently increased the volume and widening ratio at the downstream channel.

\section{2) Channel width $=20 \mathrm{~cm}, Q 2=6.64 \mathrm{~m} 3 / \mathrm{hr}$}

At day 1 a slight decrease in volume and width was observed at the end of day 1. Day 3 shows the higher flow has caused cut-off at the upstream bend that leads to higher sand deposition at $6.5 \mathrm{~m}$ and higher channel widening towards the downstream. Day 4 indicate that due to the higher flow introduced, some sediments were transported and deposited downstream. This is evident by the deposition observed between $10 \mathrm{~m}$ to $12 \mathrm{~m}$ distance.

The widening higher at the upstream section whereas the downstream section remain as in day 3. Day 6 indicates that the highest volume at $12 \mathrm{~m}$ with no significant changes of widening ratio compared to day 4 .

\section{3) Channel width $=20 \mathrm{~cm}, Q 3=8.62 \mathrm{~m} 3 / \mathrm{hr}$}

Day 1 shows the volume was in equal amount along the channel at the end of day 1 . Higher widening ratio occur at $7 \mathrm{~m}$ due to upstream bend. Day 2 indicates that overflowing of the bank was observed with evidence of bend cut-off that widen the channel at $5.5 \mathrm{~m}$ until $9 \mathrm{~m}$. The volume had increased at downstream section. Day 3 indicates that complicated braiding features was observed that contributed to higher volume and widening ratio between $6 \mathrm{~m}$ to $9.5 \mathrm{~m}$ distance. A higher volume at $11 \mathrm{~m}$ indicates that a small local deposition was observed parallel to the increasing of the channel width. At day 6, deposition remained stable but had grew in size with higher volume and widening ratio in 
comparison to day 3 .
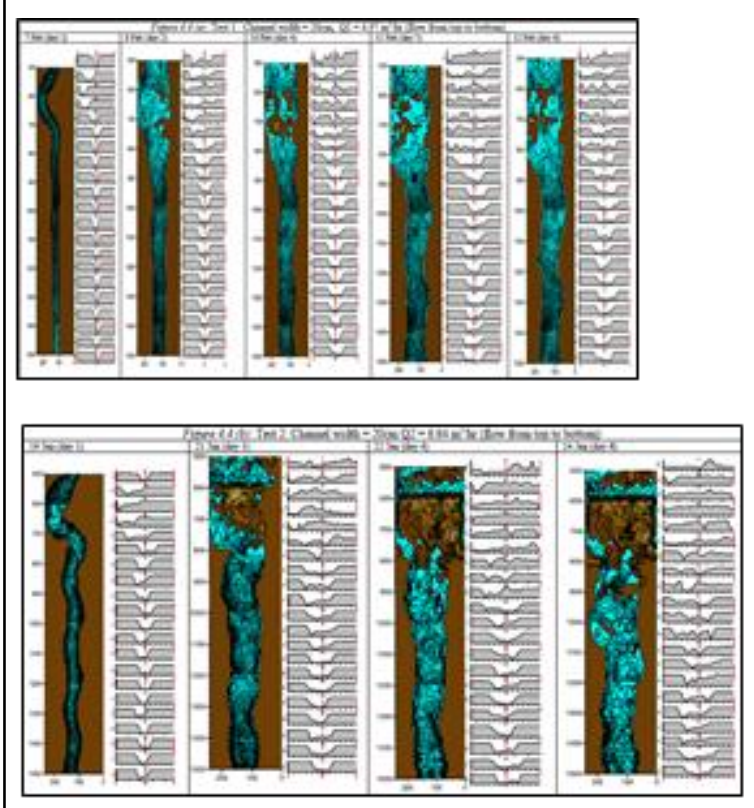

(b)
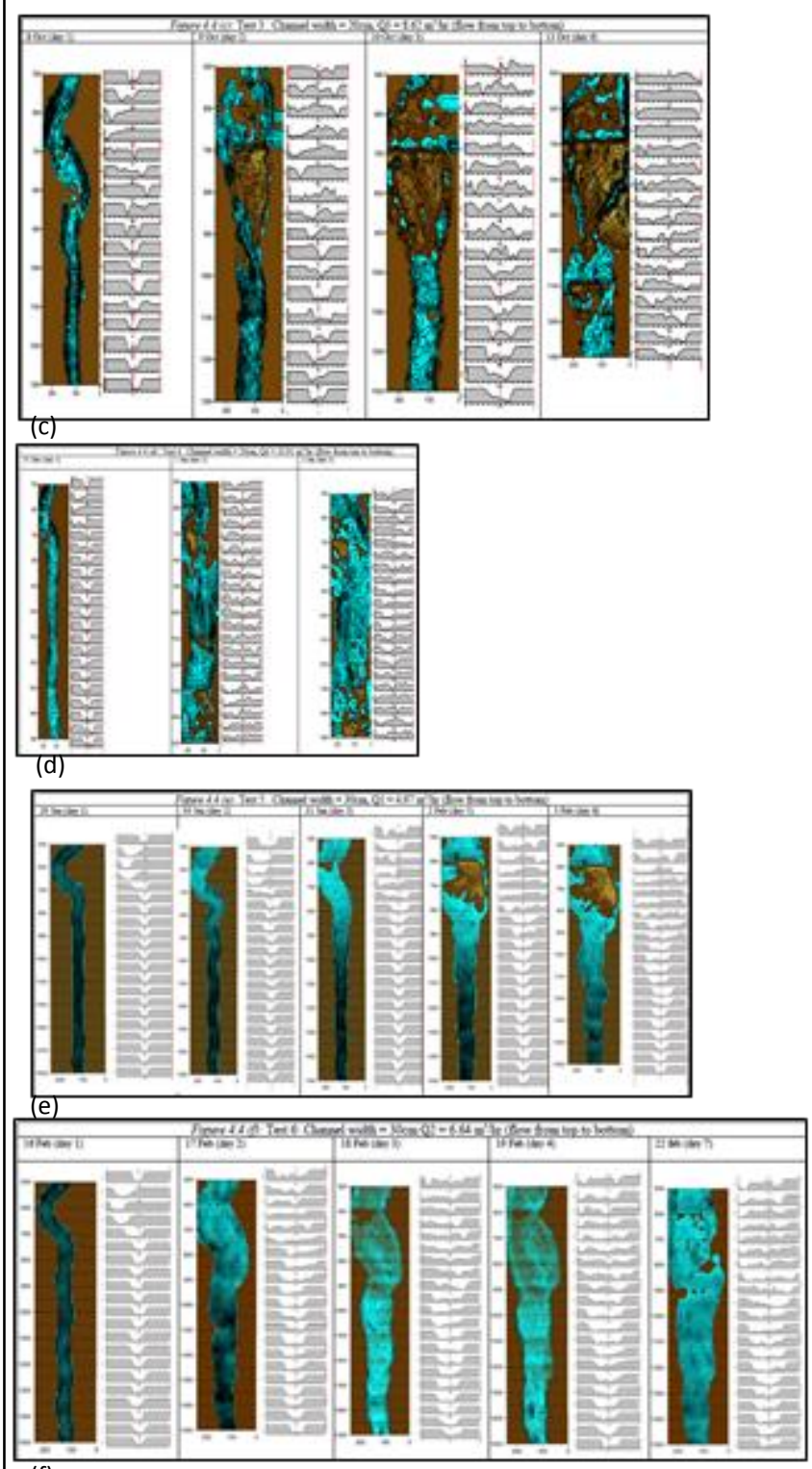

(f)
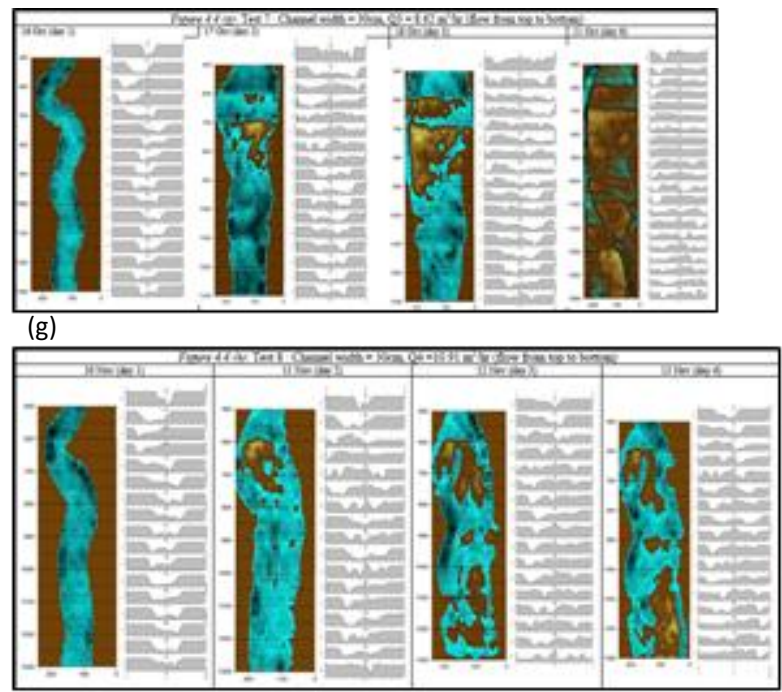

(h)

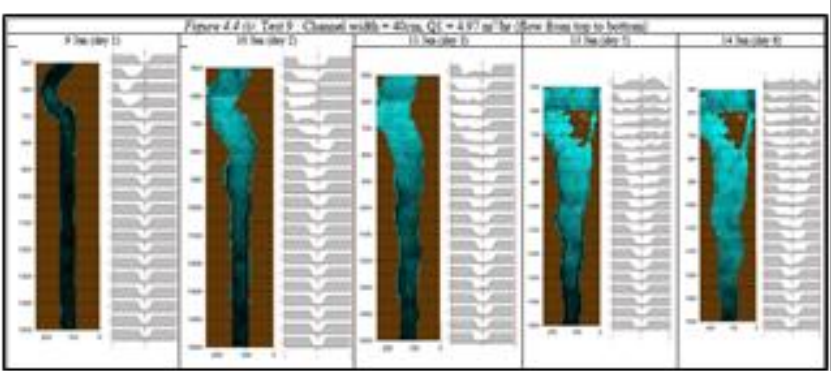

(i)
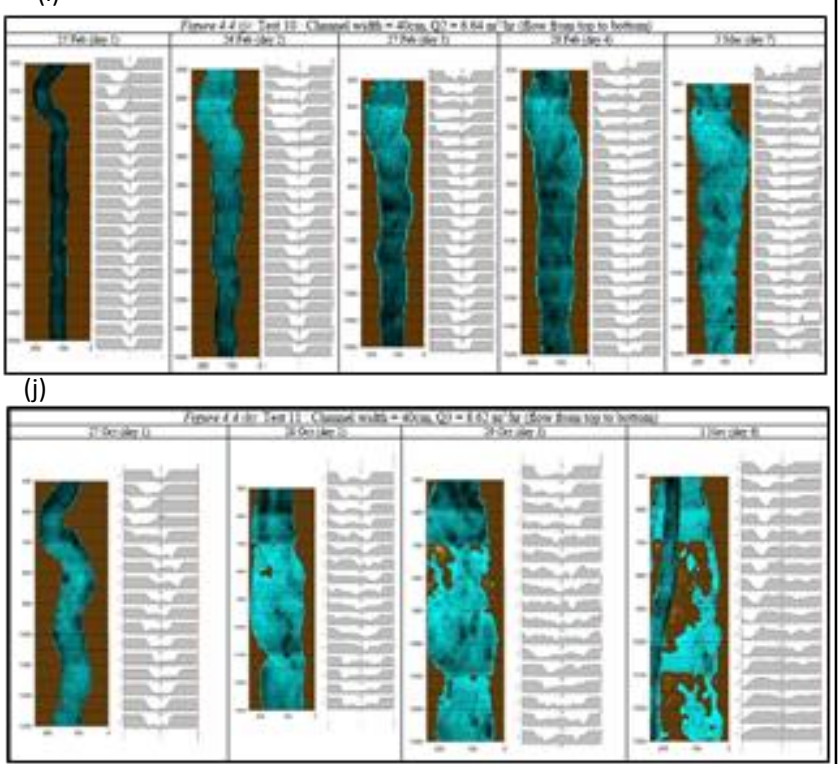

(k)

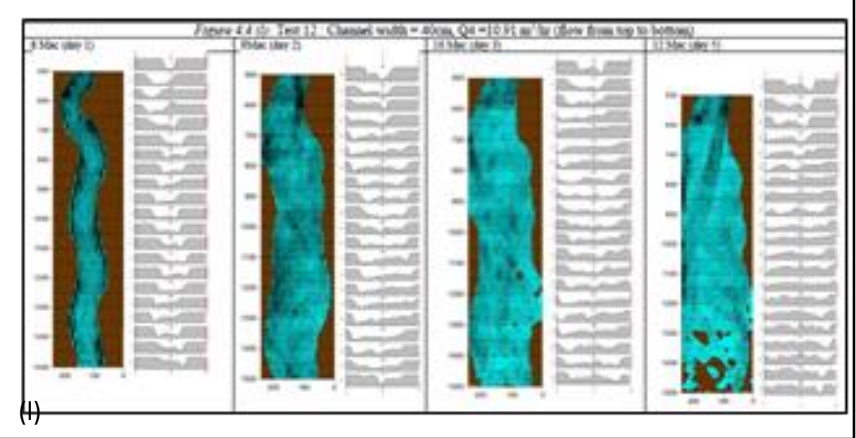

Fig. 3. (a) to (1): Cross section profile development of the different mtrices of flow rates and channel width were generated using a function in surfer. 


\section{4) Channel width $=20 \mathrm{~cm}, Q 3=10.91 \mathrm{~m} 3 / \mathrm{hr}$}

At day 1 the channel width widened and volume increased towards the downstream at the end of day 1. Day 2 shows the overflowing of the bank, complicated braiding features at the upstream bend with local deposition noted at $11 \mathrm{~m}$ and $13 \mathrm{~m}$ distance gives higher volume and widening ratio at this section. Due to higher flow rate the sediment was transported downstream with higher volume was observed between $13 \mathrm{~m}$ to $15 \mathrm{~m}$ distance at day 3 . Full expansion of channel width at point $7 \mathrm{~m}$ to $9 \mathrm{~m}$ and $12 \mathrm{~m}$ to $15 \mathrm{~m}$ downstream.

\section{5) Channel width $=30 \mathrm{~cm}, Q 1=4.97 \mathrm{~m} 3 / \mathrm{hr}$}

At day 1 the decreasing volume at $5.5 \mathrm{~m}$ was observed due to upstream bend. A small volume change at the downstream due to low flow and no significant change in width was shown at the end of day 1 . Day 2 indicates some braiding was observed at the upstream section with increasing volume from $5 \mathrm{~m}$ to $6.5 \mathrm{~m}$ point that leads to widening of the channel width. At day 3 the deposition occur at the upstream bend that lead to increase in the volume at $6 \mathrm{~m}$ to $7.5 \mathrm{~m}$ point. Increase braiding width observed at the upstream section until $11 \mathrm{~m}$ distance. At day 5 the volume increase due to larger deposition transported from upstream to downstream. Local deposition was observed at $11 \mathrm{~m}$ distance. Wider width observed at the upstream section. At day 6 the volume and widening ratio slightly higher at downstream section as compared to day 5 .

\section{6) Channel width $=30 \mathrm{~cm}, Q 2=6.64 \mathrm{~m} 3 / \mathrm{hr}$}

At day 1 shows the decreasing volume at $5.5 \mathrm{~m}$ due to upstream bend. A small volume change in the downstream channel due to low flow and no significant change of width at the end of day 1. Day 2 indicates complicated braiding features with increased volume from $5.5 \mathrm{~m}$ to $8 \mathrm{~m}$. Channel width widen along the channel was observed at day 3 Complicated braiding feature, increase the volume at $6 \mathrm{~m}$ to $7.5 \mathrm{~m}$ point. Widening of the channel width gives similar trend as compared to day 2. Day 4 illustrated the decreasing volume at upstream section due to transported sediment towards the downstream section. Deposition grew in size at $12 \mathrm{~m}$ distance. Widening channel was higher at upstream section. Day 7 indicates the increasing of volume and width starting from $9 \mathrm{~m}$ point towards the downstream section.

\section{7) Channel width $=30 \mathrm{~cm}, Q 3=8.62 \mathrm{~m} 3 / \mathrm{hr}$}

At day 1 the changes in sectional volume was observed. Volume at downstream section was higher as compared to upstream section. An increased width towards downstream section was observed at the end of day 1. Day 2 shows the complicated and wider braiding channel width contributed to higher volume at $7 \mathrm{~m}$ to $9.5 \mathrm{~m}$ point. Day 3 indicates the complicated braiding increase the volume at $6 \mathrm{~m}$ to $9 \mathrm{~m}$. Decreased width shows similar trend with day 2. Day 6 shows the decreasing of upstream volume lead to higher volume at downstream section width large deposition across the channel width observed at $13 \mathrm{~m}$ to $15 \mathrm{~m}$ distance. Widening ratio equal along the channel.

\section{8) Channel width $=30 \mathrm{~cm}, Q 4=10.91 \mathrm{~m} 3 / \mathrm{hr}$}

At day 1 the increasing in volume and width is higher in comparison to Q3. At day 2 the complicated braiding indicates the increasing volume and width at the upstream sections. At day 3 the increasing volume and width observed along the channel. Day 4 indicates the higher flow rates transported the upstream sediment and lead to volume increase between $10 \mathrm{~m}$ and $13 \mathrm{~m}$ distance. The width increase corresponds to the volume increase.

\section{9) Channel width $=40 \mathrm{~cm}, Q 1=4.97 \mathrm{~m} 3 / \mathrm{hr}$}

At day 1 the decreasing of volume at $5.5 \mathrm{~m}$ due to upstream bend was noted. A small volume change of downstream channel due to low flow. The widening ratio has no significant change at the end of day 1 . At day 2 some braiding features were observed that lead to increase in volume. The widening of the upstream bend observed at $7 \mathrm{~m}$ point. At day 3 the channel has similar volume and widening changes as in day 2. At Day 5, the cut-off at the upstream bend that leads to decreasing volume at upstream section. The widen width observed at the upstream section. At day 6 the decreasing of volume at upstream section lead to higher volume towards the downstream section. Widening ratio shows similar trend as in day 5 .

\section{0) Channel width $=40 \mathrm{~cm}, Q 2=6.64 \mathrm{~m} 3 / \mathrm{hr}$}

At day 1 the decreasing volume at $5.5 \mathrm{~m}$ was observed due to upstream bend. A small volume changes of downstream channel due to low flow. The widening ratio has no significant change at the end of day 1 . At day 2 the braiding was observed that leads to increasing in volume at the upstream section. At day 3 the complicated braiding features observed that leads to increasing of volume at point $6 \mathrm{~m}$ to $9 \mathrm{~m}$. Increasing of channel width was observed towards the downstream section. At day 4 deposition was observed between $12 \mathrm{~m}$ and $14 \mathrm{~m}$ distance indicates higher volume. The deposition stable at day 7 due to higher volume at the downstream section. Higher volume observed at downstream section due to transported sediment from upstream to downstream. Widening ratio increase towards the downstream section.

\section{1) Channel width $=40 \mathrm{~cm}, Q 3=8.62 \mathrm{~m} 3 / \mathrm{hr}$}

At day 1 the volume and widening ratio increase towards the downstream section as compared to Q2. At day 2 the complicated braiding features increase the volume. Increased channel width observed at $7.5 \mathrm{~m}$ to $11 \mathrm{~m}$. At day 3 the higher volume indicates that braiding occur until $10 \mathrm{~m}$ and the bar had started to accumulate at $11 \mathrm{~m}$. Deposition was observed between $11 \mathrm{~m}$ to $13 \mathrm{~m}$ distance. Increasing widening ratio due to channel width that has expanded to the full cross-section. Day 6 shows higher flow rates indicates that sediment transport contribute to the higher volume at the downstream section. Widening increase gradually towards the downstream.

\section{2) Channel width $=40 \mathrm{~cm}, Q 4=10.91 \mathrm{~m} 3 / \mathrm{hr}$}

The volume increase towards the downstream section as compared to Q3. The widening of channel was observed at the end of day 1 . At day 2 the complicated braiding features increased the volume and width along the channel. At day 3 the higher flow rates wash out the sediment and reduce the volume at the upstream section. This will contribute to complicated braiding features and higher deposition was observed between $13 \mathrm{~m}$ and $15 \mathrm{~m}$ distance. Increase widening 
ratio due to full expansion of channel width. At day 4 the higher flow rates had deepened the upstream section and had reduced the volume. Higher volume due to higher deposition was more evident between $13 \mathrm{~m}$ and $15 \mathrm{~m}$ distance. Full expansion of channel width observed along the channel which indicates increasing in the widening ratio towards downstream.

\section{TRend in Net Volume Change And Widening Ratio}

Trends of net volume changes and average widening ratio were illustrated in Figure 4. The net volume change is the difference between the initial volume and the final volume. There is a decreasing trend for all channel sizes at all flows towards the end of experiment. The above can be attributed to the reduction in energy to transport sediment from start to the end of the experiment. For $\mathrm{Q} 1=4.97 \mathrm{~m}^{3} / \mathrm{hr}$, the graph illustrates a little net change for the $20 \mathrm{~cm}$ channel width. This indicates that the smallest channel with the lowest flow rate remained stable and do not tend to erode. The $40 \mathrm{~cm}$ channel width shows the highest net changes for all flow rates except for flow rate $\mathrm{Q} 4=10.91 \mathrm{~m}^{3} / \mathrm{hr}$. Higher flow rates have resulted in higher net volume change due to sediment transport as compare to lower flow rates.

Widening ratio is a ratio of channel widened for each of measuring day divided by the initial channel width. Average widening ratio calculated by dividing the total widening ratio with the number of cross section along the channel that is 21 cross sections. It is being observed the increasing trends towards the end of experiment for all flow rates and channel widths. Increased average widening ratio had subsequently lead to decrease in net volume change that resulted in erosion of the banks. All flow rates on $20 \mathrm{~cm}$ channel width yield higher widening ratio.

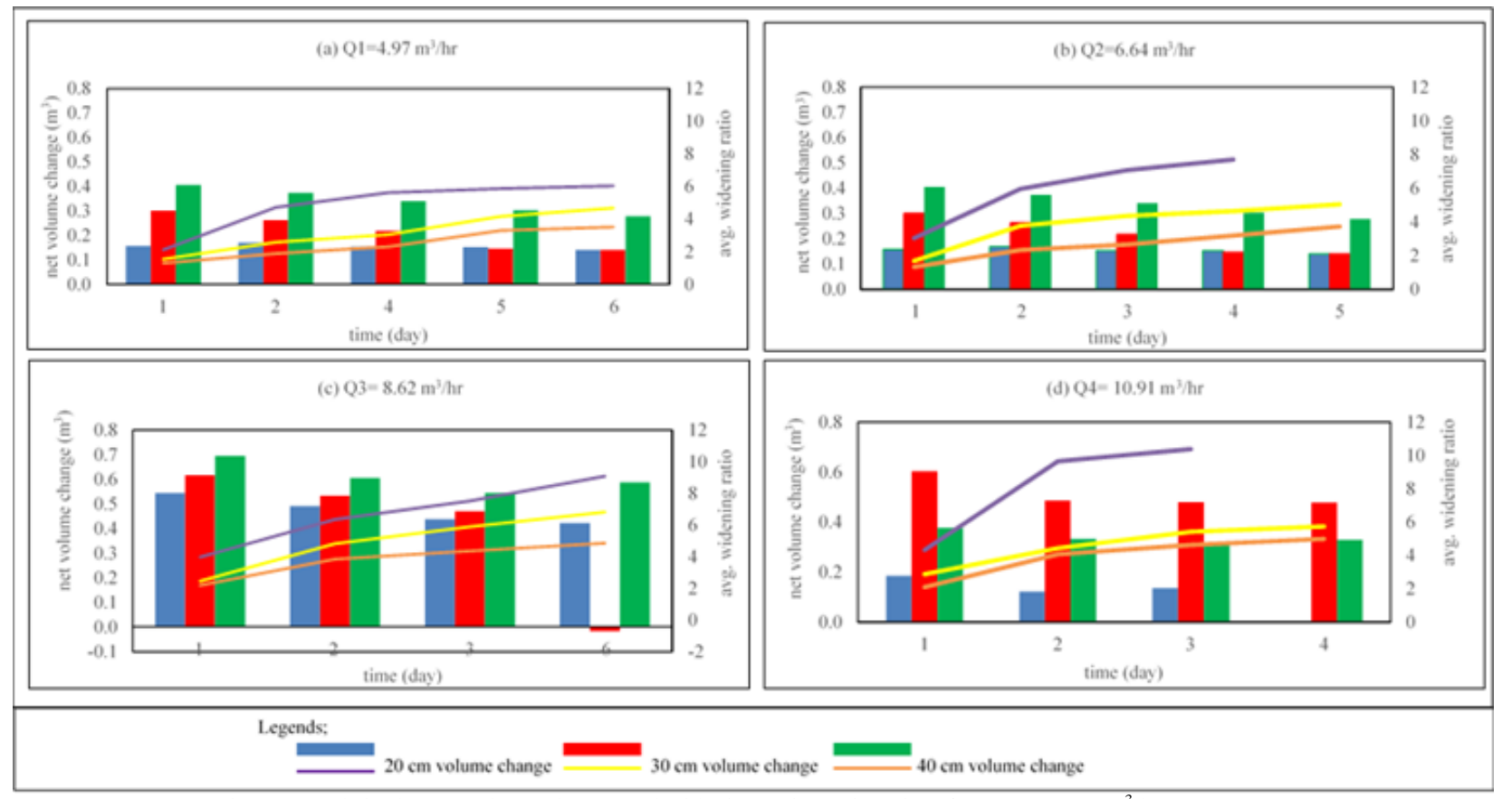

Fig. 4. Trends in the net volume change and widening ratio against time for (a) $\mathrm{Q} 1=4.97 \mathrm{~m}^{3} / \mathrm{hr}$

(b) $\mathrm{Q} 2=6.64 \mathrm{~m}^{3} / \mathrm{hr}$ (c) $\mathrm{Q} 3=8.62 \mathrm{~m}^{3} / \mathrm{hr}$ and (d) $\mathrm{Q} 4=10.91 \mathrm{~m}^{3} / \mathrm{h}$

\section{CONCLUSION}

The sectional volume changes were analysed by cross section profiles at $0.5 \mathrm{~m}$ interval along the channel. Changes in bed configuration for each cross section can be deduced from the profiles by comparing day one to the end of the experiment. Cross section profile change from upstream to the downstream are evident of rapid erosion and deposition especially in larger flow rates. Non-uniform configurations are most significant in the upper reach with evidence of cutoff at the initial bend. The downstream cross section profile for lower flow rate remain without any apparent changes. The channel widening towards the downstream of the channel will lead to the non-uniform bed configuration profiles. There is a decreasing trend for all channel sizes at all flows towards the end of the experiment. The above can be attributed to the reduction in energy to transport sediment from start to the end of the experiment. Higher flow rates have resulted in higher net volume change due to sediment transport as compared to lower flow rates.

\section{ACKNOWLEDGMENT}

The authors gratefully acknowledge the support provided by the Ministry of Higher Education Malaysia (600RMI/RAGS 5/3 (176/2014)) and Research Management Institute (RMI) of Universiti Teknologi MARA, Shah Alam, Malaysia.

\section{REFERENCES}

[1] G. Seminara and M. Tubino, "Sand bars in tidal channels," Journal Fluid Mechanics, vol. 440, pp. 49-74. 2001.

[2] P. Ashmore and G. Parker, "Confluences scour in coarse braided channel," Water Resources Research, vol. 19, pp. 392-402,1983.

[3] T. E Lisle, H. Ikeda, and F. Iseya, "Formation of stationary alternate bars in a steep channel with mixed-size sediment: A flume experiment," Earth Surface Processes and Landforms, vol. 16, pp. 463-469. 1991.

[4] P. J, Ashworth, R. I. Ferguson, P. Ashmore, C. Paola, M. Powell, and K. Prestegaard, "Measurements in a braided river chute and lobe 2. sorting of bed load during entrainment, transport and deposition," Water Resources Research, vol. 28, pp. 1887-1896,1992. 
[5] P. J. Ashworth and R. I, "Ferguson Size selective entrainment of bed load in gravel bed streams," Water Resource Research, vol. 19, pp. 392-402. 1989.

[6] J. M. Hooke, "The significance of mid channel bars in an active meandering river," Sedimentology, vol. 33, pp. 839-850. 1986.

[7] S. Lanzoni, "Experiments on bar formation in a straight flume: 1. Uniform sediment," Water Resources Research, vol. 36, pp. 3337 3349, 2000a.

[8] S. Lanzoni, "Experiments on bar formation in a straight flume: 2. Graded sediment," Water Resources Research, vol. 36, pp. 3351-3363. $2000 \mathrm{~b}$

[9] S. Lanzoni and M. Tubino, "Grain sorting and bar instability," Journal of Fluid Mechanics, vol. 393, pp. 149-174, 1999.

[10] W. Bertoldi, L. Zanoni, S. Miori, R Repetto, and M. Tubino, "Interaction between migrating bars and bifurcations in gravel bed rivers," Water Resources Research, vol. 45, pp. 1-12. $2009 \mathrm{~b}$.

[11] L. E. B. A Hong and T. R. H. Davies, "A study of stream braiding," Geological Society of America Bulletineo, vol. 90, pp. 1839-1859. 1979.

[12] P. Ashmore, "Channel Morphology and bed load pulses in braided, gravel bed streams," Geografiska Annaler, vol. 73, pp. 37-52, 1991.

[13] L. B. Leopold and M. G. Wolman, "River channels patterns; braided, meandering and straight," Physiographic and Hydraulic Studies of Rivers, pp. 1-49. 1957.

[14] S. A. Schumm and H. R. Khan, "Experimental study of channel pattern," Geological Society of America Bulletin, vol. 83, pp. 17551770, 1972.

[15] G. Parker, "Hydraulic geometry of active gravel rivers," Journal of the Hydraulic Division, American Society of Civil Engineers, pp. 1185-1201. 1979.

[16] J. H. V. D. Berg's, "Prediction of alluvial channel patterns of parennial rivers," Geomorphology, vol. 12, pp. 259-279, 1995.

[17] L. C. V. Rijn, "Sediment transport, Part III: Bed forms and alluvial roughness," Journal of Hydraulic Engineering, vol. 110, pp. 1733 1754. 1984.

[18] C. T. Yang, "Sediment transport: Theory and practice," The McGrawHill Companies, Inc. 1996.
[19] B. W Melville and S. E. Coleman, Bridge Scour, Water Resource Publications, LLC., 2000.

[20] W. Bertoldi and M. Tubino, "River bifurcations: Bed and bank evolution of bifurcating channels," Water Resources Research, pp. 112. 2005.

[21] M. Colombini and M. Tubino, "Finite-amplitude free bars: A fully non-linear spectral solution," In Sand Transport And Rivers, Estuaries And The Sea, pp. 163-169, 1991.

[22] M. Colombini, G. Seminara, and M. Tubino, "Finite-amplitude alternate bars," Journal Fluid Mechanics, pp. 213-232, 1987.

[23] P. Y. Julien, Erosion and Sedimentation, $2^{\text {nd }}$ Edition. Cambridge: Cambridge University Press. 2010.

[24] Y. Fujita and Y. Muramoto, "Studies on the process of development of alternate bars,".Bulletin of the Disaster Prevention Research Institute, vol. 35, pp. 55-86. 1985.

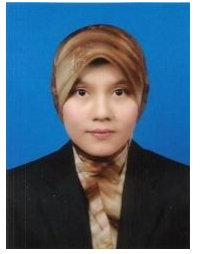

D. A. Tholibon completed her $\mathrm{PhD}$ in civil engineering, (water resource) in 2016 from Universiti Teknologi Mara, Selangor, Malaysia. Currently she served as lecturer in Universiti Teknologi Mara, Pahang, Malaysia. She has published papers in River Hydraulics Engineering. She is a member of MIEM since 2008 until present. Her research interest includes river hydraulic and river engineering.

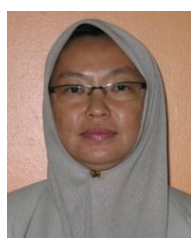

J. Ariffin received her $\mathrm{PhD}$ in 2004 from Universiti Sains Malaysia, Pulau Pinang, Malaysia. She served as a professor in Universiti Teknologi Mara, Selangor, Malaysia. She was a corporate member IEM and Professional Engineer. Her area of interests is river hydrology and flood. She has published papers in various filed such river engineering and computer technology. 